Napoleon Burt MD, B. Hugh Dorman PhD MD, Scott T. Reeves MD, Philip F. Rust PhD, * Mark L. Pinosky MD, Miguel R. Abboud MD, $†$ Julio C. Barredo MD, † Joseph H. Laver MD†

\section{Postdural puncture headache in paediatric oncology patients}

Purpose: Previous studies have not determined the correlation between dural puncture and postural headache in paediatric patients. Furthermore, no studies have evaluated the correlation between atypical headache and dural puncture in the paediatric population. Therefore, we prospectively analyzed the incidence of typical postdural puncture headache (PDPHA) and atypical headache in paediatric oncology patients following dural puncture.

Methods: The study population consisted of 66 paediatric patients undergoing 128 consecutive procedures, including 99 lumbar punctures and 29 bone marrow aspirations without concomitant lumbar puncture. Patients were prospectively randomized into four groups: Group I, preteens ( $<13 \mathrm{yr}$ ) undergoing lumbar puncture, Group II, adolescents ( $13-21$ yr) undergoing lumbar puncture, Group III, preteens undergoing bone marrow aspiration, and Group IV adolescents undergoing bone marrow aspiration. The presence and description of headache was documented immediately after dural puncture or bone marrow aspiration, and on post-procedure days \#I, 3 and 5 by personnel blinded to the type of procedure.

Results: There was an increase in the incidence of headache (9.1\%) after lumbar puncture in patients $<21$ yr relative to patients undergoing bone marrow aspiration $(P<0.05)$. No difference was found between the incidence of typical PDPHA after dural puncture in preteens and adolescents. There was also no difference in the incidence of atypical headache after dural puncture or after bone marrow aspiration among preteens and adolescents.

Conclusions: Paediatric patients experience an increased incidence of typical postdural puncture headache after dural puncture compared with age-matched patients undergoing bone marrow aspiration only. Atypical headache is relatively common in the paediatric population after dural puncture or bone marrow aspiration.

Objectif : Les études antérieures riont pas établi de corrélation entre la ponction durale et la céphalée posturale chez les patients pédiatriques. En outre, aucune étude de cette population n'a évalué le lien entre la céphalée atypique et la ponction durale. Par conséquent, à la suite d'une ponction durale, nous avons analysé de façon prospective l'incidence d'une céphalée de ponction postdurale (CPPD) typique et atypique chez des patients d'oncologie pédiatrique.

Méthode : La population de l'étude était constituée de 66 patients de pédiatrie subissant 128 examens consécutifs, comprenant 99 ponctions lombaires et 29 ponctions médullaires sans ponction lombaire concomitante. Les patients ont été répartis au hasard en quatre groupes de façon prospective: Groupe I de pré-adolescents (< 13 ans) subissant une ponction lombaire; Groupe II d'adolescents (13-2I ans) subissant une ponction lombaire; Groupe III de pré-adolescents inscrits pour une ponction médullaire et Groupe IV d'adolescents pour une ponction médullaire. La présence de céphalée a été vérifiée et décrite immédiatement après la ponction durale ou la ponction médullaire et 1,3 et 5 jours suivant les interventions par du personnel qui ignorait le type de technique employé.

Résultats : Il y a eu une incidence accrue de céphalée $(9, \mid \%)$ à la suite de la ponction lombaire chez les patients < $2 \mathrm{l}$ ans par rapport aux patients qui ont subi une ponction médullaire $(P<0,05)$. Aucune différence n'est apparue dans l'incidence de CPPD typique après une ponction lombaire chez les pré-adolescents et chez les adolescents. II n'y avait pas non plus de différence dans l'incidence de céphalée atypique après une ponction durale ou une ponction médullaire parmi les pré-adolescents et les adolescents.

Conclusion : Les patients de pédiatrie ont connu une incidence accrue de céphalée de ponction postdurale à la suite d'une ponction durale quand on les compare aux patients du même âge qui ont subi une ponction médullaire seulement. La céphalée atypique est relativement fréquente dans la population pédiatrique après une ponction durale ou une ponction médullaire.

From the Department of Anesthesiology, Department of Biostatistics and Epidemiology, ${ }^{*}$ and Department of Pediatrics, $\dagger$ Medical University of South Carolina, 171 Ashley Avenue, Charleston, South Carolina 29425-2207 USA.

Address correspondence to: Napolcon Burt MD, Phone: 843-792-2322; Fax: 843-792-2726; E-mail: burtn@musc.edu

Accepted for Publication May 25, 1998. 
$\mathrm{L}$ UMBAR puncture is required for a variety of diagnostic and therapeutic purposes, and it is also a common route of anaesthetic administration. However, post-dural puncture headache (PDPHA) may occur after lumbar puncture. The classic type of postdural headache is frontal or occipital in distribution, exacerbated by head elevation, and may be associated with nuchal stiffness, nausea, vomiting, tinnitus, or blurred vision. ${ }^{1-5}$ Although PDPHA has been characterized in adults, ${ }^{6-12}$ few studies have addressed the incidence of PDPHA in paediatric patients. ${ }^{13-15}$ Moreover, wide discrepancies in the incidence $(3-78 \%)$, severity and definition of PDPHA in the paediatric population suggest the need for clarification. Furthermore, there is a widespread belief that PDPHA does not occur in children less than ten years of age. ${ }^{17,18}$ The primary purpose of this study was to examine prospectively the incidence of classic PDPHA in paediatric patients undergoing lumbar puncture.

Atypical headache also occurs after dural puncture. These atypical PDPHAs are characterized by the absence of exacerbation upon standing or sitting. ${ }^{18,19}$ Atypical headaches have been described in studies of PDPHA involving adult patients with an incidence ranging from $4-17 \%{ }^{20-26}$ However, only one previous study has attempted to identify the incidence of these headaches after dural puncture in paediatric patients. ${ }^{14}$ The second purpose of this study, therefore, was to establish the incidence of atypical PDPHA in paediatric patients following lumbar puncture, and compare this with that in paediatric patients undergoing bone marrow aspiration without lumbar puncture.

\section{Methods}

Institutional IRB approval was obtained for 66 paediatric patients presenting for 128 consecutive procedures in the paediatric oncology suite, consisting of 99 dural punctures or 29 consecutive bone marrow aspirations without concomitant dural puncture. Parental consent for follow-up questioning was obtained prior to each procedure. Patients with acute or chronic sinusitis, a headache upon presentation for the procedure, a history of recurrent, chronic headache, or patients receiving chronic pain medication were excluded from the study. The paediatric patients were prospectively divided into four groups based on age and type of procedure (Table I). Group I consisted of patients < $13 \mathrm{yr}$ (preteens) undergoing dural puncture. Group II consisted of patients 13-21 yr (adolescents) undergoing dural puncture. Group III consisted of 14 patients < $13 \mathrm{yr}$ of age who underwent bone marrow aspiration only. Group IV consisted of 9 adolescent patients 13-21 yr of age who underwent bone marrow aspiration only. Dural punctures were performed with 20 or 22 gauge needles by senior haematology/oncology fellows (Table I). Five to $10 \mathrm{ml}$ of cerebrospinal fluid were routinely removed during dural puncture. Intrathecal chemotherapy was administered to $87 \%$ of patients in Group I and $86 \%$ of patients in Group II. The primary disease in the study population was acute lymphoblastic leukaemia (Table II). Other diseases among the paediatric population included lymphoma (8), Ewing's sarcoma (4), neuroblastoma (2), idiopathic thrombocytopenia (2) and aplastic anaemia (1).

All children were fasting for the procedure; the ingestion of solid food was discontinued for eight hours and clear liquid intake was prohibited for two hours prior to the procedure. After the procedure, clear liquid intake was not restricted. Anaesthesia for all procedures consisted of intravenous sedation with midazolam-ketamine or midazolam-alfentanil-propofol while maintaining spontaneous ventilation. Routine monitors included ECG, non-invasive blood pressure, continuous pulse oximetry, and precordial stethoscope. Supplemental oxygen was provided as needed to maintain oxygen saturation $>97 \%$. Following dural puncture or bone marrow aspiration, patients were discharged home or admitted to the inpatient paediatric haematology/oncology ward as indicated by their post-procedure status and need for further diagnostic evaluation or treatment. At the time of discharge/transfer, the following data were collected: 1) behaviour, 2) the presence/absence of headache, 3 ) description of headache (if headache was present), and 3 ) additional medication administered.

Anaesthesia personnel, blinded to the type of procedure, contacted parents by telephone on post-procedure days 1,3 , and 5 to discuss the previous $24-48 \mathrm{hr}$ events. Behaviour, activity level, appetite, and the presence of nuchal rigidity or headache were investigated during these telephone interactions, which permitted better distinction of classic PDPHA and associated symptomatology from atypical headache. A classic PDPHA was diagnosed if the headache was aggravated by sitting or standing in children over two years. In patients two years of age or less, a PDPHA was diagnosed by refusal to remain sitting in association with cranky behaviour, decreased activity, or nuchal rigidity. Atypical headaches were only defined in children over two years. These were headaches which had no postural component and had other apparent causes (dehydration, viral syndrome).

For statistical analysis, more structure was incorporated into the data analysis. With the four groups representing a crossing of presence/absence of dural puncture with age category, a $2 \times 2 \times 3$ table was con- 
TABLE I Demographic characteristics and spinal needle gauge

\begin{tabular}{lllllllll}
\hline & & \multicolumn{2}{c}{ Age } & \multicolumn{2}{c}{ Sex } & \multicolumn{2}{c}{ Needle size } \\
\hline Group & Patients $(\mathrm{n})$ & Procedures $(\mathrm{n})$ & median & range & $\mathrm{M}$ & $\mathrm{F}$ & $20 \mathrm{~g}$ & $\mathbf{2 2 \mathrm { g }}$ \\
I & 33 & 70 & 4 & $2-11$ & 52 & 18 & 7 & $63^{*}$ \\
II & 10 & 29 & 16 & $13-21$ & 17 & 12 & 16 & 13 \\
III & 14 & 15 & 6 & $2-12$ & 13 & 2 & - & - \\
IV & 9 & 14 & 14 & $13-19$ & 4 & 10 & - & - \\
\hline
\end{tabular}

$* P<0.05 ; 20$ vs 22 gauge

TABLE II Oncologic diagnoses in the pacdiatric study population

\begin{tabular}{lll}
\hline Group & Leukaemia & Diagnosis \\
& Other \\
\hline I & 62 & 8 \\
II & 29 & - \\
III & 8 & 7 \\
IV & 12 & 2 \\
\hline
\end{tabular}

TABLE III Incidence of post dural puncture headache (pdpha) and atypical headache among paediatric oncology patients

\begin{tabular}{lccccc}
\hline & Number of Procedures & \multicolumn{3}{c}{ PDPHA } & \multicolumn{3}{c}{ Atypical headache } \\
& & M & F & M & F \\
Group I & 70 & 3 & 1 & 6 & 7 \\
Group II & 29 & 2 & 3 & 3 & 2 \\
Group III & 15 & - & - & 1 & 0 \\
Group IV & 14 & - & - & 2 & 0 \\
\hline
\end{tabular}

structed. Log-linear models are typically fitted to three-dimensional tables: in this case a model assuming no associations among variables and another that permits expression of a headache $v s$ dural puncture association were constructed. The test was also presented in simplified form by combining the classic PDPHA with the atypical headaches, producing a $2 \times 2 \times 2$ table. Both three-dimensional tables are constructed from the data in Table III. Log-likelihood $\mathrm{G}^{2}$ statistics, which follow an approximate chi-square distribution were obtained from BMDP4F software (Los Angeles, CA). Chi- square analysis was performed for these statistical comparisons. Statistical significance was defined as $P<0.05$.

\section{Results}

There was no difference in patient age (Table I) between Groups I and III (preteens) or between Groups II and IV (adolescents). Group I consisted of 33 children with a median age of four years who underwent 70 dural punctures, while Group II consisted of 10 children with a median age of $16 \mathrm{yr}$ who underwent 29 dural punctures. Group III consisted of 14 patients with a median age of six years who underwent bone marrow aspiration only, and Group IV consisted of nine patients with a median age of $14 \mathrm{yr}$, who also only underwent bone marrow aspiration. There was increased utilization of $\mathbf{2 2}$ gauge spinal needles relative to 20 gauge needles in Group I $(P<0.05)$; in Group II the incidence of dural puncture with 20 and 22 gauge needles was similar (Table I). In $77 \%$ of patients in Group I and $52 \%$ of patients in Group II dural puncture was successful on the first attempt. More than three attempts were required for successful dural puncture for $7 \%$ of patients in Group I and 17\% of patients in Group II.

The incidence of headache after dural puncture was increased compared with the coincidence of headache after bone marrow aspiration $(P<0.05)$. The incidence of PDPHA associated with lumbar puncture was $9.1 \%$ with an incidence of $5.7 \%$ for patients in group I and $17 \%$ for patients in group II (Table III). The incidence of classic PDPHA experienced by patients in group I was not different from that experienced by patients in group II. No classic PDPHA occurred in patients in group III or IV.

The incidence of atypical headache after lumbar puncture was similar between patients in group I (preteens, 18.6\%) and in group II (adolescents, 17.2\%) (Table III). One patient experienced an atypical headache after bone marrow aspiration in Group III (7.1\%) and two patients experienced atypical headaches after bone marrow aspiration in Group IV (22.2\%). The incidence of atypical headache was not increased in patients who underwent dural puncture.

\section{Discussion}

We prospectively evaluated the incidence of PDPHA and atypical headache following dural puncture in paediatric patients and compared the incidence of headache with that in paediatric patients undergoing bone marrow aspiration. The unique findings from this study were three-fold: 1) there was an increased incidence of headache in paediatric patients undergoing dural puncture compared with patients undergoing bone marrow aspiration, 2) the incidence of PDPHA was similar in preteens and adolescents, and 3 ) the incidence of atypical headache was not increased after dural puncture in paediatric patients. 
The incidence, onset and severity of PDPHA in adults has been well studied. ${ }^{6-8,19,20,27}$ In general, female sex, large spinal needles, and decreased age are associated with an increased incidence of PDPHA in adults. ${ }^{18,20-22,28,29}$ However, few studies have evaluated and characterized PDPHA in children. Moreover, paediatric studies have yielded wide discrepancies in the incidence and severity of PDPHA. In two separate studies no PDPHA was observed in patients $<10 \mathrm{yr}$ of age utilizing $\# 20$ and $\# 22$ gauge needles. ${ }^{17}$ The incidence of PDPHA in other studies ranged from 3 to $78 \% .{ }^{13-15}$ In the present study, PDPHA occurred in $5.7 \%$ of pre-teen patients and in $17 \%$ of adolescents. Differences in the incidence of PDPHA in paediatric studies may, in part, be the result of methodology for data acquisition. Previous studies utilized postal questionnaires that were filled out by the parents over a variable number of days. In the present study, parents were directly contacted and questioned on days 1,3 and 5 after lumbar puncture, which may result in improved specificity for detection of PDPHA and allow for clarification of headache presentation, especially in young children. In addition to the type of follow-up, other factors that may contribute to observed differences in paediatric PDPHA among studies include the number of days studied post-puncture, the number of patients studied, the removal of various quantities of cerebrospinal fluid, the gauge and type of spinal needle, exclusion criteria and age distribution. Although $90 \%$ of PDPHAs occur within the first three days after dural puncture, it is necessary to evaluate patients for at least five days post-puncture since the onset of PDPHA can be delayed. ${ }^{5}$

The incidence of PDPHA in the present study was similar in pre-teens $(5.7 \%)$ and adolescents $(17 \%)$. However, the sample size of Group II was less than half that of Group I and patient numbers may have been too snall to detect a difference, resulting in a Type II error. Although, there was an increased number of dural punctures performed with \#22 gauge needles in the pre-teen population, there was no evidence that this affected the incidence of headache. A logistic regression analysis with headache as the response was performed and needle gauge was not a significant covariable. This held true whether the analysis was done for PDPHA ( $P$ $=0.97)$, or for all headaches $(P=0.55)$. However, diagnosis of PDPHA in the preverbal child is difficult and may result in underestimating the true frequency of PDPHA in a child less than 2 years of age. It was not possible to enroll additional paediatric patients in the headache study due to a declining patient census and, therefore, the possibility of a Type II error in the analysis of PDPHA between Groups I and II is impossible to exclude. This study, therefore, illustrates that PDPHA commonly occurs following dural puncture, even in paediatric patients $<12 \mathrm{yr}$ of age.

The incidence of atypical headache was also examined in paediatric patients who underwent dural puncture and compared with that in patients who underwent bone marrow aspiration only. Atypical headache included all headaches other than PDPHA. Classification of atypical headache according to diagnosis (ie. tension $v$ s migraine) may have provided more useful information. Only one previous study has examined atypical headache following dural puncture in children. ${ }^{14}$ Although the incidence of atypical headache in the present study was not increased after lumbar puncture, the incidence of atypical headache was higher than reported by Bolder in which atypical headache after lumbar puncture was $14 \%$ for pre-teens, but did not occur in the adolescent population. ${ }^{14}$ In contrast, in the present study, the incidence of atypical headache was $18.6 \%$ for pre-teens and $17.2 \%$ for the adolescent population. In adult studies of atypical headache after lumbar puncture, the incidence ranges from 2.5 to $14 \%$, with most studies reporting in the $4-7 \%$ range. ${ }^{18,19,21-26}$ The increased incidence of atypical headache in the present study may be due to study design in which direct verbal contact was initiated with parents on days 1,3 and 5 for interrogation about headache symptomatology. Moreover, the administration of intrathecal chemotherapeutic agents in $86 \%$ of patients in the present study may have contributed to the higher incidence of atypical headache. It is important to note that atypical headache was also prevalent in patients who underwent bone marrow aspiration only. Other factors that probably contributed to the development of atypical headache include anaesthesia and the chronic disease process. Thus, the results from this study illustrate that atypical headache occurs frequently in the paediatric population after both dural puncture and bone marrow aspiration, which suggests that directed questioning for headache symptoms is warranted after these procedures to facilitate treatment.

Since patients underwent repeat procedures, a headache with the first experience may have biassed the results of subsequent procedures. In Group I there was one repeat PDPHA and one repeat atypical headache. In both cases, the children also underwent several procedures without headache. In Group III and IV there were no repeat headaches. However, in Group II one child had a repeat PDPHA, and no procedure without PDPHA. It is possible, especially in the adolescent population, that an initial headache may have biassed the patient during subsequent procedures. 
In summary, PDPHA occurs commonly in the paediatric population, including patients under the age of 12 years. Atypical headache is also prevalent in paediatric oncology patients undergoing lumbar puncture and occurs frequently in paediatric patients undergoing bone marrow aspiration only. The observation that paediatric patients experience both PDPHA and atypical headache after lumbar puncture may not be common knowledge among paediatricians and other paediatric primary care givers, which may necessitate educational intervention by anaesthetists.

\section{References}

1 Leibold RA, Yealy DM, Coppola M, Cantees KK. Postdural-puncture headache: characteristics, management, and prevention. Ann Emerg Med 1993; 22: 1863-70.

2 Reynolds F. Dural puncture and headache. Avoid the first but treat the second. BMJ 1993; 306: 874-5.

3 Ozdil T, Powell WF. Post lumbar puncture headache: an effective method of prevention. Anesth Analg 1965; 44: 542-5.

4 Raskin NH. Lumbar puncture headache: a review. Headache 1990; 30: 197-200.

5 Gielen M. Post dural puncture headache (PDPH): a review. Reg Anesth 1989; 14: 101-6.

6 Dittmann $M$, Renkl F. Spinal anesthesia with extremely fine needles (Letter). Anesthesiology 1989; 70 : 1035-6.

7 Tourtellotte WW, Henderson WG, Tucker RP, Gilland $O$, Walker JE, Kokman E. A randomized double-blind clinical trial comparing the 22 versus 26 gauge needle in the production of the Post-Lumbar Puncture Syndrome in normal individuals. Headache 1972; 12: 73-7.

8 Kuntz KM, Kokmen E, Stevens JC, Miller P, Offord KP, Ho MM. Post-lumbar puncture headaches: experience in 501 consecutive procedures. Neurology 1992; 42: 1884-7.

9 Sarma VJ, Boström U. Intrathecal anaesthesia for daycare surgery. A retrospective study of 160 cases using 25- and 26-gauge spinal needles. Anaesthesia 1990; 45: 769-71.

10 McSwiney M, Pbillips J. Post dural puncture headache. Acta Anaesthesiol Scand 1995; 39: 990-5.

11 Carbaat PAT, van Crevel $H$. Lumbar puncture headache: controlled study on the preventive effect of 24 hours' bed rest. Lancet 1981; 2: 1133-5.

12 Vilming ST, Scbrader H, Monstad I. Post-lumbar-puncture headache: the significance of body posture. Cephalalgia 1988; 8: 75-8.

13 Vandam $L D$, Dripps $R D$. Long-term follow-up of patients who received 10,098 spinal anesthetics. JAMA 1956; 161: 586-91.
14 Bolder PM. Postlumbar puncture headache in pediatric oncology patients. Anesthesiology 1986; 65: 696-8.

15 Plaut TF. Lumbar puncture in children: its value and risk. Clin Ped 1968; 7: 130-3.

16 Wee $L H$, Lam $F$, Cranston AJ. The incidence of postdural puncture headache in children. Anaesthesia 1996; 51: 1164-6.

17 Fembach DJ. Headache after lumbar puncture (Letter). Lancet $1981 ; 2: 529$.

18 Flaatten $H$, Raeder J. Spinal anaesthesia for outpatient surgery. Anaesthesia 1985; 40; 1108-11.

19 Geurts JW, Haanschoten MC, vanWijk RM, Besse TC. Post-dural puncture headache in young patients. A comparative study between the use of $0.52 \mathrm{~mm}$ (25-gauge) and $0.33 \mathrm{~mm}$ (29-gauge) spinal needles. Acta Anaesthesiol Scand 1990; 34: 350-3.

20 Flaatten $H$, Rodt S, Rosland J, Vamnes J. Postoperative headache in young patients after spinal anaesthesia. Anaesthesia 1987; 42: 202-5.

21 Lynch J, Arhelger S, Krings-Ernst I. Post-dural puncture headache in young orthopedic in-patients: comparison of a $0.33 \mathrm{~mm}$ (29-gauge) Quincke-type with a $0.7 \mathrm{~mm}$ (22-gauge) Whitacre spinal needle in 200 patients. Acta Anaesthesiol Scand 1992; 36: 58-61.

22 Brattebø $G$, Wisborg $T$, Rodt $S \AA$, Bjerkan $B$. Intrathecal anaesthesia in patients under 45 years: incidence of postdural puncture symptoms after spinal anaesthesia with 25G needles. Acta Anaesthesiol Scand 1993; 37: 545-8.

23 Dahl JB, Schultz P, Anker-Moller E, Cbristensen EF, Staunstrup HG, Carlsson P. Spinal anaesthesia in young patients using a 29-gauge needle: technical considerations and an evaluation of postoperative complaints compared with general anaesthesia. Br J Anaesth 1990; 64: 178-82.

24 Lynch J, Krings-Ernst I, Strick K, Topalidis K, Schaaf $H$, Fiebig $M$. Use of a 25 -gauge Whitacre needle to reduce the incidence of postdural puncture headache. Br J Anaesth 1991; 67: 690-3.

25 Vilming ST, Schrader H, Monstad I. The significance of age, sex and cerebrospinal fluid pressure in post- lumbar-puncture headache. Cephalalgia 1989; 9: 99-106.

26 Flaatten $H$, Rodt SA, Vamnes J, Rosland J, Wisborg $T$. Postdural puncture headache. A comparison between 26- and 29-gauge needles in young patients. Anaesthesia $1989 ; 44: 147-9$.

27 Sand T, Stovner LJ, Salvesen R. Side effects after diagnostic lumbar puncture and lumbar iohexol myelography. Neuroradiology 1987; 29: 385-8.

28 Lesser P, Bembridge M, Lyons G, MacDonald R. An evaluation of a 30-gauge needle for spinal anaesthesia for Caesarean section. Anaesthesia 1990; 45: 767-8.

29 Frumin MJ. Spinal anesthesia using a 32-gauge needle. Anesthesiology 1969; 30: 599-603. 